\title{
The Role of Data Warehouse as a Source of Knowledge Acquisition in Decision-Making. An Empirical Study
}

\author{
Moh'd Alsqour ${ }^{12}$, Mieczysław L. Owoc ${ }^{13}$ \\ 1 Wroclaw University of Economics \\ Komandorska 118/120, \\ 53-345 Wrocław, Poland \\ 2 Email: mohsqour@wp.pl \\ 3 Email: mieczyslaw.owoc@ue.wroc.pl
}

\begin{abstract}
The main purpose of conducting this research is to investigate empirically the role and importance of data warehouse (DW) in enhancing the effectiveness of decision-making. It is believed and assumed that meaningful and significant information can be acquired from DW which provides valuable knowledge to support business process and decision-making. A mail questionnaire survey was regarded as the appropriate method for gathering data. The questionnaire was developed based on the findings from related literature and other related research questionnaires. All the firms (277), which were listed on Amman Stock Exchange (ASE), at the time of data collection, were selected. The researchers arrived at scores of significant and remarkable results regarding DW and its role in enhancing the process of decision-making. The survey's findings showed that the percentage of implementing DW in the Jordanian firms involved is $35 \%$. In general, the respondents had a positive attitude towards the implementation of DW.

Keywords: Data warehouse., Decision-making, Information, Decision-makers
\end{abstract}

\section{Introduction}

Today's organizations face a very hard time, largely as a result of competition, globalization, automation and scarcity of resources. As the business environment is changing. Companies rely more and more on changing technology. At the same time, those companies are likewise evolving. In this changing environment, companies are much more eager in getting immediate and accurate information to make better decisions. Successfully supporting managerial decision-making has become critically dependent upon the availability of integrated and high quality information organized and presented to managers in a timely and easily understood manner [1].

Nowadays there is a need for more advanced and accurate systems. Today's systems are more likely to produce more accurate information than previous systems. Traditional systems, indubitably, are more likely to produce less accurate data and information which lead to bad and incorrect decisions. However, the situation will be different if the firms implement data warehouse (DW) technology, which has emerged as a key source and powerful tool for delivering and accessing information 
for decision-makers [1], [2], [3], [4]. Since the 1990s [5], DWs have been an essential information technology (IT) strategy component for large and medium-sized global organizations [5].

Large organizations are facing significant challenges in maintaining an integrated view of their business [6]. In an ever more complex and competitive world, the complexity of the organizational context and the management task involving decision-making and assessment of information has increased [7]. Moreover, the changing business environment has an impact on the nature of decisions and decisionmaking drivers [12]. Timely and informed decision-making is becoming crucial for the long-term success of businesses [13]. [14] claims that business decisions must be made with speed and accuracy if organizations are to remain competitive. Decisionmaking in those environments involves large data volumes and includes a wide variety of decision tasks [8]. In such environments it is important to assure decisionmakers of the quality of data they use [8], [13].

There is quasi-consent that DW provides more detailed and accurate information for decision-makers to improve their decisions. DW systems are perceived to be important tools in the modeling of that complexity. [10] claim that DW hastens the process of retrieving information needed for decision-making. However, reports of high failure of DW systems are common [5], [7], [9].

Despite the recognition of data warehousing as an important area of practice and research, there is little empirical research [1] about implementation of DW in general [1], [9], [11]. Considering the usefulness of DW there has been little research in Jordan on DW, i.e. it has been comparatively less investigated in Jordan. Therefore, the main focus of this study is on the advantages of DW as a provider of information to the process of decision-making. It investigates mainly the relation between decision-making, the need for information and the employment of DW in Jordanian firms. In addition, this study investigates how top management of Jordanian firms perceives the effectiveness (usefulness) of DW as a source of reliable and accurate information for decision-making. Although many studies to DW have been published, they have been concerned with technical issues. However, it has been understood recently that the information systems (IS) failure is due to psychological, environmental, organizational issues etc. rather than technological issues, hence individual differences must be addressed [15]. Overall, there is a scarcity of empirical studies that examine the data warehousing success within an integrative model [9].

\section{The Study's Aims}

In this research paper, a field study of DW and its role in easing and enhancing the process of strategic decision-making among top managers in Jordanian firms were investigated. Therefore, the main aim of this study is to investigate the role, which is played by DW, in decision-making. In realizing this aim, the researchers believe that the following matters in particular deserve careful investigation largely due to their close connection with the aim and its achievement:

1. To investigate the relationship between the implementation of DW by Jordanian firms and the effectiveness of strategic decision-making (assuming that there is a 
positive association between the implementation of DW and the degree of decision performance).

It has been ascertained that DW is superior to traditional database and improves the process of decision-making. Therefore, one of the study's aims is to investigate empirically whether or not the DW provides better and more accurate information. It is anticipated in this study that the enhancement of decision-making's process might drive Jordanian firms to employ DW. Thus, another aim of this study is to identify the Jordanian firms' reasons for implementing DW.

2. To identify the grounds of implementing DW by Jordanian firms.

A study of a large number of data warehousing practitioners and experts by [16] showed that the implementation of DW was motivated more by internal pressures than external. A majority of the respondents said that the need was information related. [17] are of the opinion that improving access to information and delivering better and more accurate information are motivations for using DW.

\section{The Study's Questions and Hypotheses}

The hypotheses are formulated in the light of the study theoretical and conceptual framework and partially based on related previous studies. It is assumed that the outputs of DW, such as data and information, have more positive effect on the process of decision-making by comparison with traditional database systems. This assumption leads the researchers to question whether there is a direct positive relationship between improving the process of decision-making and the implementation of DW? In other words, does the DW provide relevant, reliable and sufficient information for decision-makers to take and achieve sound and effective decisions? This question leads to hypothesis 1 .

Hypothesis 1: There is a strong association between employing DW in Jordanian firms and improving the process of decision-making (soundness and effectiveness of decisions).

In addition to the principal objective of this study, the researchers attempt to achieve multiple aims through this study, including the grounds, which drove Jordanian firms, of implementing DW. This aim led to question what the Jordanian firms' grounds of implementing DW are. This question, in turn, led the researchers to formulate hypothesis 2 .

Hypothesis 2: The dearth of reliable information for taking decisions, the highly competitive environment, the need for more accurate, reliable, relevant and timely information, the changes in manufacturing technology, techniques and processes, the unreliability of existing systems of decision support and inability of the existing systems of decision support to provide reliable, useful and relevant information to the process of decision-making are the major grounds of implementing DW in Jordanian firms. 


\section{The Importance of the Study}

This study was applied in Jordan, which is one of the developing countries in the Middle East. As Jordan's firms are not in isolation from the rest of the world, they are also influenced by the current competitive environment. The implementation of advanced and recent innovations, such as DW, is essential for the firms in developing economies, such as Jordan. Therefore, investigating their implementation in Jordanian firms is well worth considering. However, a few empirical studies, which had been identified on Jordanian firms, prompted the researchers to examine whether this innovation has been successfully implemented in Jordan. Because of the need for further investigation on this topic, considering its importance and the shortage of the empirical research, the researchers have every reason to investigate this issue which has not been given the proper attention in Jordanian environment. Despite the exaltation and adulation of DW, There is a need for evidences that the implementation of DW improves the quality and accessibility to information. Therefore, this study aims to practically investigate whether or not the implementation of DW improves the quality and accessibility to information and enhances the process of decision-making. [18] drew attention to the role and importance of information accessibility. The authors claim that the information accessibility is a precursor of information quality-it has a significant impact on the information's usage, and consequently is an indicator of the DW's success in storing and processing information.

In addition to information's quality, previous literature and studies on DW have emphasized the importance of accessing information. The accessibility to information and their quality are crucial to the success of their use. It has been claimed that the use/ implementation of DW improves the quality and accessibility to information, and consequently leads to sound decisions. In other words, it leads to more fact-based decisions. DW has, according to DW literature, the ability to store a vast amount of data in a usable and appropriate form for the decision-makers' needs and uses. Although a wide range of primary and secondary sources has emphasized the importance and role of information quality and accessibility in enhancing the process of decision-making, little empirical research has been conducted so far. Such claims need to be tested empirically. It is essential, therefore, that the researchers investigate whether or not DW provides easy access to data and information, frequent, accessible and timely reports and more accurate, useful, reliable, complete and relevant information to decision-makers.

Based on extensive literature review, the researcher has identified that firms are often unsuccessful due to a lack of appropriate information or more precisely their inability to get the right information to the right person at the right time. The availability of apposite information to decision-making helps managers in taking reliable decisions, which improve the firm's performance. For this reason, this study is one of the few empirical studies (e.g. [4]), which attempts to examine the effect of DW on decision effectiveness. In addition, previous research has not empirically tested its effectiveness in DSSs contexts in Jordanian firms "to the researchers' knowledge".

Additionally, the researchers have not found and are completely unaware of any empirical studies regarding the implementation of DW in Jordan. Therefore, it is hoped that the findings of this study give the readers and those who are interested in 
these issues practical insights into DW's field in Jordan. To some extent, it is one of the academic contributions. It contributes to our understanding of the DW in general and in Jordan in particular, and may form a basis and motivation for future research in the important fields. It is also believed that the final outcome of this paper adds up to the improvement and development in DSS, such as DW, by helping their users and developers to be more aware of the data and information's quality.

\section{Research Methodology}

The study is passed in different phases. In the initial phases of the study, renowned journals, publications, conferences proceedings and books were reviewed. In addition to these sources, the findings of numerous empirical studies were researched and analyzed. Based on the literature review the study' hypotheses were formulated. As the researchers previously pointed out, the sample of the study comprises all the 277 firms, which are listed on ASE at the time of the data collection. Thus, a questionnaire was found to be the best instrument for collecting the data in this study. During the next phases, therefore, a survey questionnaire was conducted with the top managers of Jordanian firms. The questionnaire, which is used in this study, is based on previous studies and the researchers' assessments and discretion and adapted to suit the objectives and requirements of the study. The primary objective of the questionnaire is to amass appropriate data and responses from the potential respondents for testing the significance of hypotheses.

In order to answer the study's questions, fulfill its aims and find out whether or not there is a positive relationship between independent and dependent variables, the study's hypotheses were statistically tested. The data, which were collected, is very quantitative in nature.

Therefore, in the final phases of the study, the data were statistically analyzed by employing Statistical Package for the Social Sciences (SPSS) in order that proper descriptive and inferential statistics to analyze the results and draw conclusions can be reached, including means, frequencies, standard deviation, $\mathrm{t}$ - test, f-test and chisquare.

\section{5 literature Review}

The concept of data warehousing has evolved out of the need for easy access to a structured store of quality data that can be used for decision-making [19 p. 5]. Organizations have vast amounts of data but have found it increasingly difficult to access it and make use of it. This is because it is in many different formats, exists on many different platforms, and resides in many different file and database structures, and, as a result, organizations have had to write and maintain perhaps hundreds of programs that are used to extract, prepare, and consolidate data for use by many different applications for analysis and reporting [19 p. 5].

As an attempt to solve the problem, DWs were introduced. DWs have become the focal point for decision support in organizations today [20] and emerged as a key 
platform for the integrated management of decision support data in organizations [3]. [19 p. 5] claim that the data warehousing offers a better approach. Data warehousing implements the process to access heterogeneous data sources; clean, filter, and transform the data; and store the data in a structure that is easy to access, understand, and use. The data is then used for query, reporting, and data analysis [19 p. 5]. [21] also claim that the data warehousing has emerged as an effective mechanism for converting data into useful information.

DW systems offer efficient access to integrated and historical data from heterogeneous sources to support managers in their planning and decision-making [22]. [23] also claim that data warehousing provides an infrastructure that enables businesses to extract, cleanse, and store vast amounts of data. According to [19 p. 1], businesses of all sizes and in different industries, as well as government agencies can realize significant benefits by implementing a DW. Most medium to large organizations, according to [24], operate DWs.

It has been claimed that the main DW's role is to support decision-making. However, the role of DWs has been broadened. [25] state that DW provides information from external data sources for decision-making. DW has the potential to create radical changes to existing business processes and is often viewed within the context of business process reengineering [11]. Accordingly, [26] claims that DW gives business' users the ability to analyze data. [27] also claim that DWs enable organizations to exploit decision-making.

According to [28], DWs provide the basis for management reports and decision support. They added that the purpose of DWs is to take that vast amount of data from many internal and external sources and present them in meaningful formats for making better decisions. In support of the above mentioned claims participants to a study by [3] agreed that the Return on Investment (ROI) for the DW was well justified through considerable gains in productivity and enhanced quality of customer service. Moreover, in an independent detailed study of 62 organizations worldwide [34], the major findings of International Data Corporation (IDC) based upon 62 case studies of organizations that have successful DWs in use are an average three-year ROI of 401percent was realized by organizations building DWs. Although this study is primarily focused on quantitative information, there are several qualitative benefits [34], such as providing standardized, clean and value-added data to create information from disparate sources. In addition, the DW makes the data available across corporate organizations and provides the needed information quickly.

The DW is developed in order to support the integration of external data sources [29] for the purpose of advanced data analysis. [40 p. 35] argues that a DW produces tangible impacts to the quality of day-to-day business transactions. Previous research on DW has produced some encouraging findings about its benefits and indicated that a DW can offer several benefits to an organization [11], such as enabling effective decision support; ensuring data integrity, accuracy, security, and availability; easing the setting and enforcing of standards, facilitating data sharing, and improving customer service [35]. [30] presented time savings for data suppliers and for users, more and better information, better decisions, improvement of business processes, and support for the accomplishment of strategic business objectives as benefits from data warehousing. Furthermore, [2], who examined data warehousing at the Housing and Development Board (HDB) in Singapore, found that the main benefits of the DW, 
which were developed by HDB, are enabling the users to have access to consistent and reliable data in a timely fashion which facilitated forecasting and planning efforts and improved decision-making. In addition, a study by [31] revealed that DW appears to be used more to improve the flow of information in an organization than to change the way the organization does business. The authors found that more and better data is the greatest realized benefit from DW. Moreover, a study by [32] identified time savings, new and better information, and improved decision-making as benefits of DW.

[33] conducted an explanatory case study at a financial services organization to investigate how DW provides decision support to individual decision-makers. The results showed that the organizations successfully automated the retrieval and input of data for front-end users. [40 p. 33-34], who interviewed people from seven companies, found that the benefits of implementing DW were improving asset management, reducing customer support costs, auditing billing practices, terminating unprofitable product, reducing staff requirements and running the business. [28], who described the DW implementation at Blue Cross and Blue Shield of North Carolina (BCBSNC), claim that the DW had resulted in many organizational benefits, including better data analysis and time savings for users. [34], who looked at the DW of Egypt's Cabinet Information and Decision Support Center, found that the DW provides a lot of benefits to the users, including ease of access to the information, fast and more consistent reports, support the decision-makers and integrating the data from various sources.

Additionally, [4], who conducted a laboratory experiment in 2006, found that the implementation and use of DW improves the DSS users' decision performance, by which he means improving the quality of the DSS by adding a DW can improve information availability and quality and enhance DSS users' decision performance. In conclusion, the study showed that DW can have a positive impact on decisionmaking.

[35], who described an example of implementing DW in medical institutions, found that the DWs provide the users access to important information. [36], who conducted a survey to find out how DW assists decision-making process in healthcare, found that the DW provides better accessibility to data, integrated disparate data sources and improved decision-making. [37] found that all companies, which are studied, recognized some benefits such as cost reduction, reach-out to other markets, increase in sales, time saving in amount and preparation of reports and more effective decision-making based on the obtained information. [38], who conducted two case studies on American Airlines and Hallmark Cards, found the easy to use, speedy information retrieval, more information, better quality information, improved productivity, and better decisions as benefits of DW. [39], who examined the implementation of DW in public security, found that the DW is very important in improving the comprehensive ability of leadership and decision-making. In addition, it quickly and efficiently integrates heterogeneous data sources.

Previous literature on DW, such as [31] and [22], claims that the DW does not create value by itself; the value comes from the use of the data in the DW. [22] claim that improved decision-making results from the better information available in the DW. By making the right information available at the right time to the right decisionmakers in the right manner, DWs empower the users with the ability to make the right 
decisions [40]. [31] also claim that this use can result in numerous benefits, including more and better information, improved user ability to produce information and reduced effort by developers to produce information. [41] also maintain that DWs have tremendous potential to present information. The greatest potential benefits of the DW occur when it is used to redesign business processes and to support strategic business objectives [30]. [42] also identified many different measures of success; these include benefits such as data accuracy, useful information, accurate information, ease of use, user satisfaction, time to make decision and increased revenue. However, [43] claims that despite clear evidences that many DW projects have resulted in interesting business benefits, there are also many examples of cost and schedule overruns and dissatisfaction regarding the results from these projects. [44] argue that DW is one of the key developments in the IS field and has plentiful benefits. In addition, [45] indicates that the introduction of a new IS into an organization should deliver multiple benefits.

Since the early 1990s, DWs have become the technology of choice for building data management infrastructures [5] and been investigated and implemented around the world in many areas and by many researchers, authors, and scholars [46]. According to [47 p. 13], the early successful implementation of DW dates back to mid-1980s at ABN AMRO Bank (Netherlands). The author claims that the end-user's needs were the key feature behind the implementation. As a result, those requirements were modeled rather broadly, and all available data was stored in the DW. In fact, in the first few years of general use, its usage had grown at an annual rate of $50 \%$, and by 1995 the DW had supported some 3,000 end-users. [47 p. 17] also mentioned that a study of 62 DW projects, which was conducted in 1996, showed an average return on investment (ROI) of $321 \%$ for these enterprise-wide implementation in an average payback period of 2.73 years.

In addition, [48], who investigated whether lodging companies are involved with DW technology through a sample of twelve large lodging corporations, found that the most of hotel corporations in the study were using their DWs to support market analysis. However, [13], who conducted a survey on a large Australian public organization, found that $60 \%$ of the users were with limited or no usage (or were anticipating the use in the future) of the DW. The data also helped the users to make informed decisions and the data, which was retrieved from the DW, was also presented to the senior management and other strategically oriented sections in the form of reports i.e. annual and quarterly reports.

Similarly, [11], who surveyed DW's managers and data suppliers from 111 organizations in different regions of the United States (US), also found that all companies had operational DW and nearly all of them considered that their initiative is successful. In other words, $26 \%$ of the respondents considered it runaway success. Another survey by Forrester showed that 878 IT decision-makers in the US enterprises were somewhat satisfied with the accessibility and quality of customer information; $82 \%$ of these respondents are satisfied or very satisfied [49]. [27] also found that about $55 \%$ of 196 respondents firms (107) in two major states in the US had already adopted and used DWs. Similarly, [23 p.192-196) found that $60 \%$ of the respondents consider the functionality of their DW below expectations. $40 \%$ of the dissatisfied group was actually still using it. This means that $80 \%$ of the respondents 
were still using their internal DW, which is a good indication of the overall degree of satisfaction.

In addition to those studies, [50], who reported the results of a survey which was conducted at The Data Warehousing Institute (TDWI) World Conference in New Orleans 2003 , found that $45 \%$ of the respondents had been already in production with their current DW or implementing a second or third release. In Taiwan, [51], who conducted a survey on Taiwanese banks, found that $53.33 \%$ of 30 respondent banks had DW functions or capabilities, $31.25 \%$ (5) out of 16 respondent banks had already implemented the DW and $68.75 \%$ (11) were still in the process of development to implement DW. 85.71\% (12) of 14 banks which had not implemented the DW were evaluating the possibility and/or potential of adopting DW. Another study in Asian countries was conducted by [52]. [52], who surveyed 115 users of DW in four Korean financial companies, also found that the participated companies had been using their data warehousing systems for approximately two years. In addition, the findings also showed that all the respondents were end-users of DWs in their companies, using the systems mainly for financial analyses. The majority of data warehousing users (approximately 70-75\%) use the DWs regularly, i.e. every day.

The 2007's IBM Data Warehousing Satisfaction Survey showed that $56 \%$ of those questioned were very successful with their DW (200 end-user enterprises were participated), however, $43 \%$ of the respondents acknowledged the need for improvement, as there are still a number of business and technical challenges confronting the enterprises which make use of DWs according to the survey [53]. The success of DW's implementation, according to [53], is growing as $56 \%$ of the respondents were very successful and satisfied. [54], who conducted a survey on 84 users of DW, found that the majority of respondents $(73 \%)$ in the surveyed firm were successful in obtaining and accessing the needed data and information from the DW, only two respondents indicated that they were not at all successful, while $56 \%$ indicated somewhat successful and $13 \%$ indicated very successful. In addition to these results, $67 \%$ and $33 \%$ of the respondents rated the importance of the obtained information in performing their job better as vital and somewhat important respectively.

Numerous studies have also shown successful implementation of DW. For example, [55] used a case study and conducted a series of interviews at Continental Airlines. The results showed that the organization has realized an enviable level of DW maturity and significant cumulative benefits. [56], who surveyed 244 members of TDWI, found that $51.2 \%$ of the respondents had at least one DW application and $30.3 \%$ were still in development stage. $17.2 \%$ were still in planning stage and $1.2 \%$ of respondents had no any efforts made in their organizations to implement the DW. This result showed that more than $80 \%$ of respondents had implemented DW.

According to [9], there is a scarcity of empirical studies that examine the DW success. In the study population, i.e. Jordan, there is not a shred of empirical evidence that the DW has been investigated or showed the degree of DW implementation, to the best of the researchers' knowledge. However, the literature review was limited to materials which have been published in English language only-evidence in languages other than English could be possible. Therefore, this paper investigates the extent to which Jordanian firms implemented DW and the reasons for implementing DW. It is 
aimed at providing empirical evidence, thereby extending the body of research regarding the implementation of DSSs in general and DW in particular.

\section{Findings and discussion}

As mentioned earlier, the study's sample consists of the Jordanian firms' top management. [57 p. 142) claim that although the large populations are referred to as ideal populations, sampling every person in these populations is not realistic or doable. They believe that time, money, and other restrictions make it impossible for the average survey researcher to reach all members of an ideal population. Therefore, the researchers have to forgo these grand expectations and select a smaller or realistic population. This argument forms the basis for this study's population, therefore, the study's population, which is selected, is only the Jordanian firms that are listed on ASE.

It is believed that this category is more likely to use the outputs of DW for strategic decision-making, i.e. the data, which is obtained from these respondents, fulfill the purpose of this study. Therefore, the potential respondents were solicited for their opinions. The covering letter was addressed to the top management of each firm. The questionnaire, along with a self-addressed stamped envelope (SASE) and a covering letter were posted to the potential respondents. The potential respondents were requested to return the completed questionnaires in the enclosed SASE.

As the main aim of this study is to investigate the role of DW in strategic decisionmaking, the choice of the target population (Jordanian firms which are listed on ASE) and potential respondents (top management) is made on the basis that those firms have sufficient resources to implement such expensive and time-consuming systems and the respondents have sufficient knowledge about their firms and take the strategic decisions. In other words, they are the main consumers of the DW reports. In addition, the companies' Guide by ASE is the only listing that specifically covers all sectors and industries in Jordan. This directory lists the names, titles, and the general information about the listed companies. Top management of Jordanian firms, which are listed on ASE, constitutes the population of this study. A total of 277 questionnaires were sent out by post along with a covering letter. The potential respondents were assured that all data, which would be provided by them, would be treated by complete confidentiality.

The results of the study's sample analysis are shown in the figure below (Fig. 1). In this figure, the sample results are broken down by responses. As can be seen from these results, 140 completed questionnaires were returned to the researcher's address with a response rate of $50.5 \%$. According to these figures, usable questionnaires accounts for $43.3 \%$ of the total sample. 20 of the questionnaires were discarded as unreliable, i.e. there were many essential questions missing from the questionnaires.

To sum up, all the firms (277), which were listed on ASE at the time of data collection, were selected. 140 filled questionnaires were returned generating $50.5 \%$. This response rate somehow on average comparison to many similar studies such as [58], [59]. [58], who studied 350 Jordanian companies, had a response rate of $30 \%$. 
[59], who used a self-administered questionnaire and targeted similar population in Jordan, had a response rate less than $50 \%$.

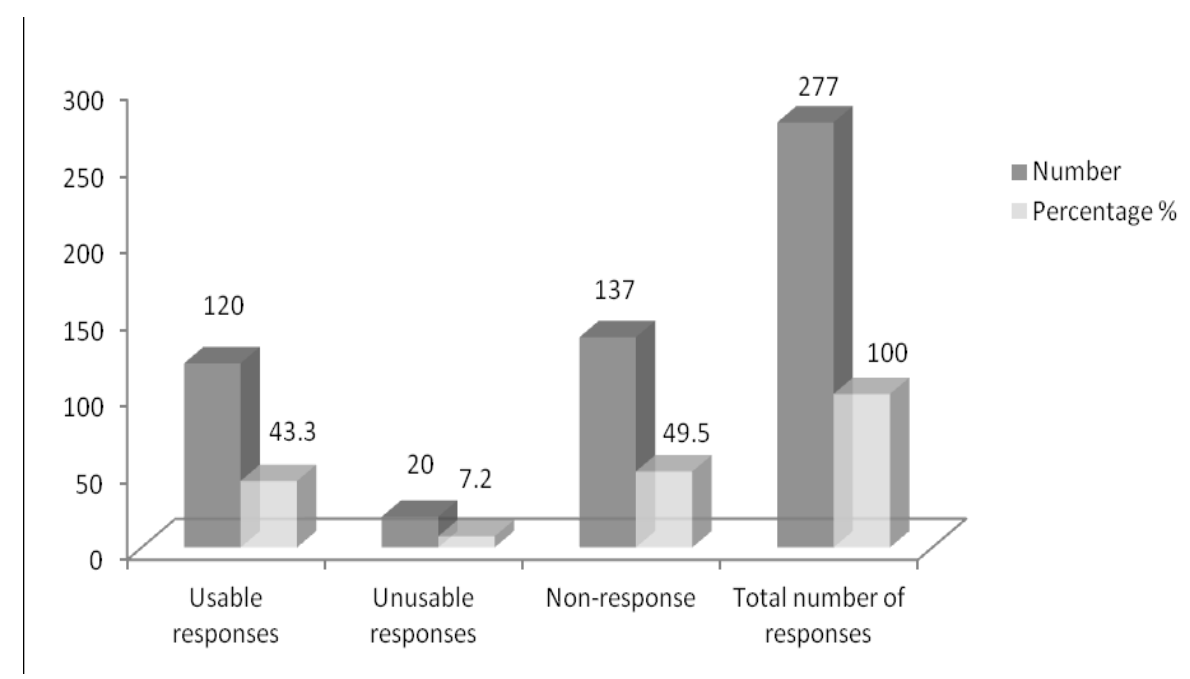

Fig. 1. The analysis of the study's sample (Source: the figures are based on the responses to the survey).

The reliability, internal consistency and validity of the Likert scale questions are assessed by using Cronbach's alpha. Figure 2 shows Cronbach's alpha for the two

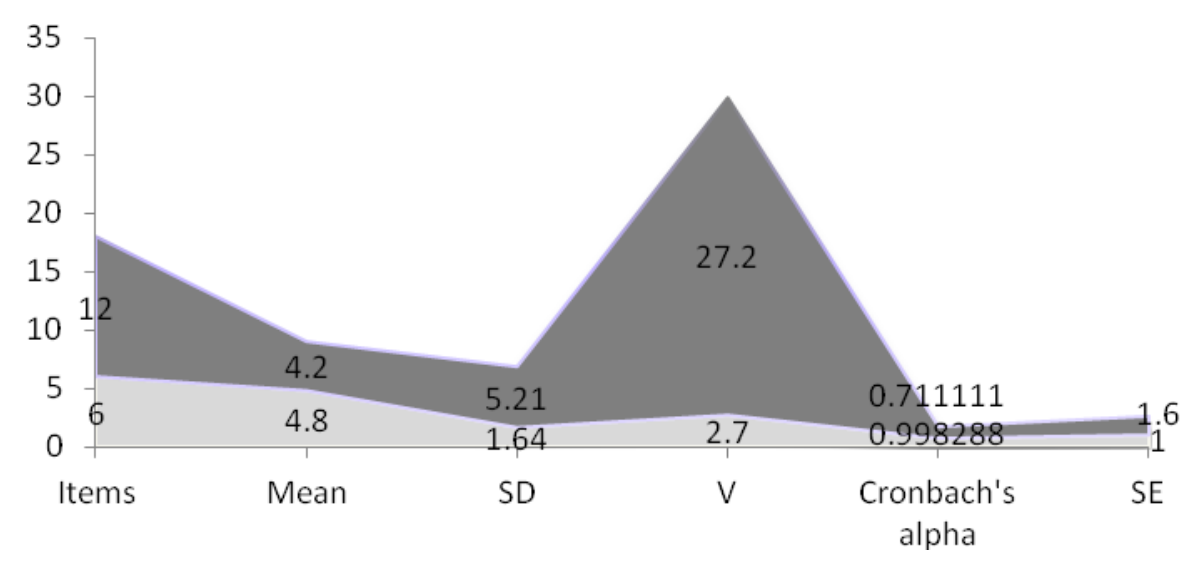

Fig. 2. The analysis of the study's sample (Source: the figures are based on the responses to question 11 and question 12 (appendix A)).

Likert-scale questions. In addition, the table demonstrates the mean, SD, sum of item variances (V) and standard error (SE) for the rating scale questions. It was found that 
Cronbach's alpha is the most popular method for assessing the reliability of scales. It has been used by many researchers, including [60], [61], [62], [63], [64], [65], [66], [67], [68], [69], [70], [71]. Cronbach's alpha determines the internal consistency of the items in a survey instrument (questionnaire) to assess its reliability [72], [73], [74].

The types of the firms involved in this survey are illustrated by a bar chart (figure $3)$. In this bar chart, the survey results are broken down by industry group.

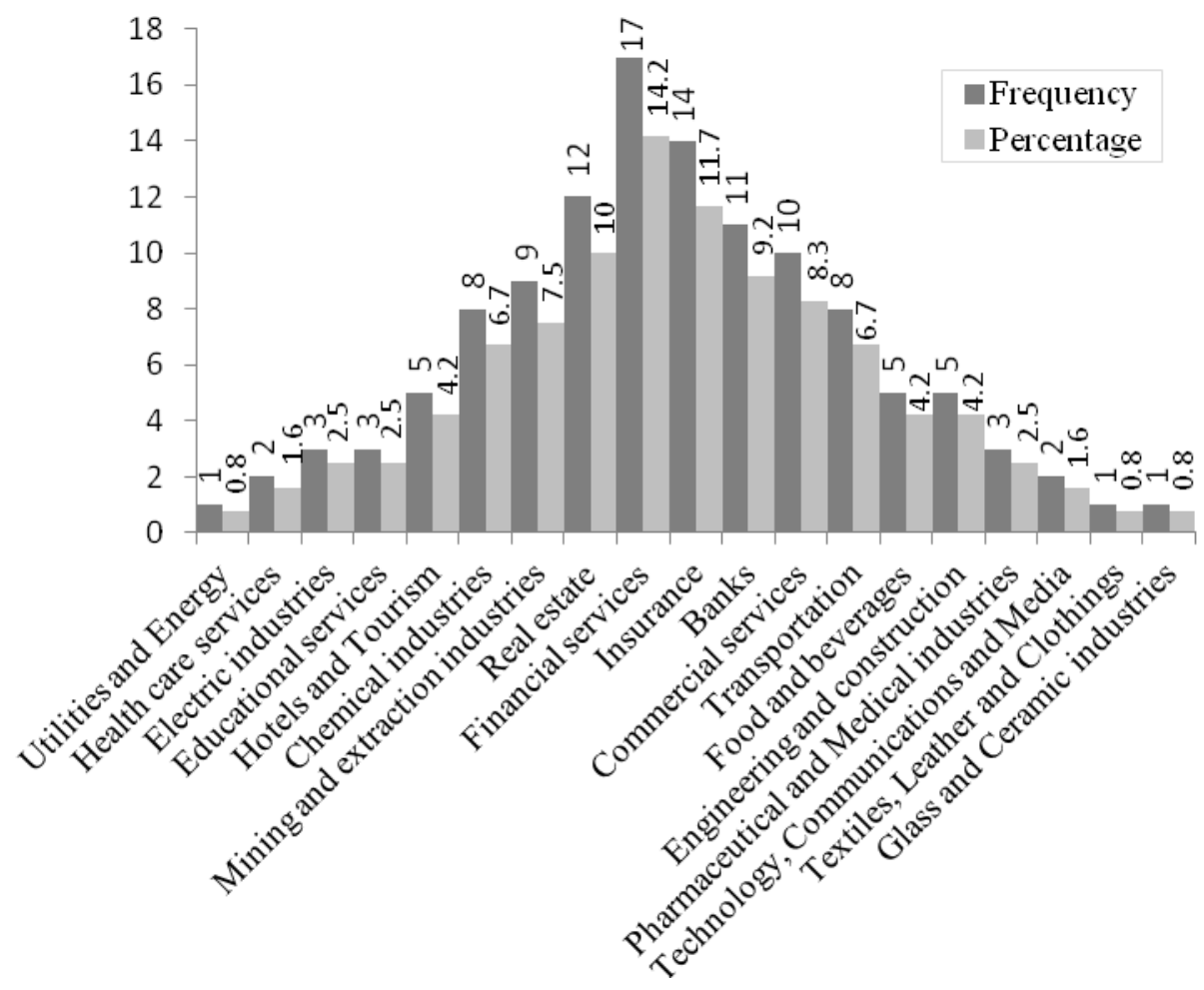

Fig. 3. The industry groups of the firms involved (Source: the chart is based on figures from question 6 (appendix A)).

As can be seen from these results, the financial services industry is the highest among the others (14.2\%). According to these figures, the insurance industry accounts for $11.7 \%$ of the industry groups. The survey's figures also show that $9.2 \%$ of the firms are within the banking industry, considerably higher than the $0.8 \%$ of firms within the glass and ceramic, textile, leather and clothing and utilities and energy industries and $2.5 \%$ within the pharmaceutical and medical, electric and educational services industries. From the data in the above bar chart, it is apparent that almost 9 industries are in the range of 3 to 10 per cent. 
For the purpose of this study, there are only two groups regarding the implementation of DW: first, the firms that have fully implemented DW and used it as a part of daily practices; and, second, the firms that have not implemented DW.

The pie chart (Figure 4) illustrates how many firms implemented DW. As can be seen from these results, the number and percentage of the firms, which have not implemented DW, are far more than those which implement.

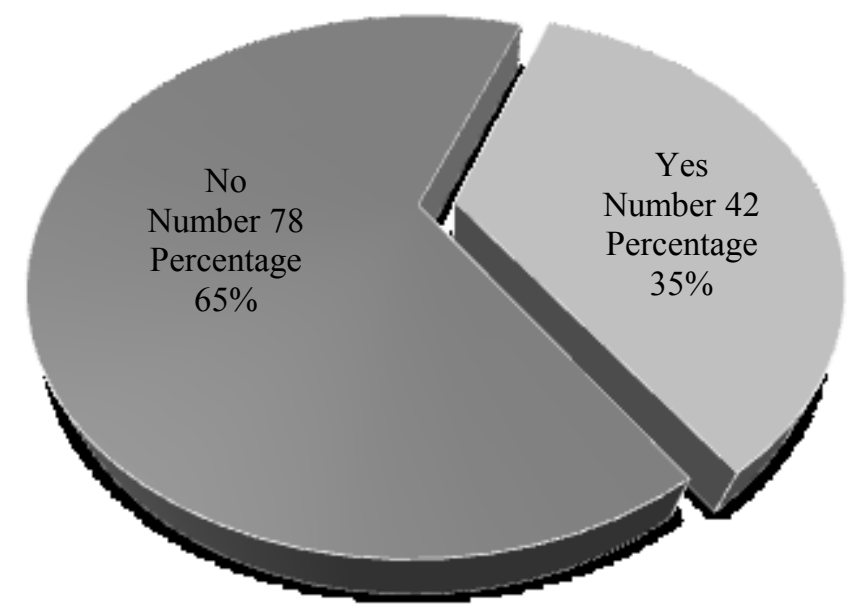

Fig. 4. The percentage of implementing DW among the firms involved(Source: the figures are based on the responses to question 10 (appendix A)).

According to this bar chart, only approximately a third (42) of Jordanian firms involved has implemented DW. In other words, $35 \%$ of the firms involved have implemented DW. The firms, which have not implemented DW, make up about $65 \%$ of the 120 firms involved in the survey. The results of the study revealed that the rate of implementing DW in Jordanian firms is very low and less than other countries. For example, [27] found that about 55\% of 196 respondents firms (107) in two major states in the continental US had already adopted and used DWs. [56], who surveyed 244 members of TDWI, found that $51.2 \%$ of the respondents had at least one DW application. However, the results of this study are similar to some previous studies' results. For example, [51], who conducted a survey on 16 Taiwanese banks, found the rate of implementing DW among those banks is $31.25 \%$.

The 42 respondents, who their firms implemented DW, were solicited for their opinions regarding the reasons behind the plan (decision) to implement a DW. The likely and expected reasons, which were measured on a five-point scale ranging from 1 (unimportant) to 5 (extremely important), are shown in Table (1). The table shows the mean and standard deviation (SD) for all the select reasons. 
Table 1. The Reasons for Implementing DW (Source: the figures are based on the responses to question 11 appendix A.

\begin{tabular}{|l|r|r|r|r|c|}
\hline \multicolumn{1}{|c|}{ The reasons for implementing DW } & NO. & Min. & Max. & Mean & SD \\
\hline $\begin{array}{l}\text { There is a dearth of reliable information } \\
\text { for taking decisions }\end{array}$ & 42 & 2 & 5 & 4.07 & 0.97 \\
\hline $\begin{array}{l}\text { The highly competitive environment } \\
\text { created the need to replace the existing } \\
\text { systems of decision support }\end{array}$ & 42 & 1 & 4 & 2.59 & 1.11 \\
\hline $\begin{array}{l}\text { The need for more accurate, reliable, } \\
\text { relevant and timely information }\end{array}$ & 42 & 3 & 5 & 4.28 & 0.81 \\
\hline $\begin{array}{l}\text { Changes in manufacturing technology, } \\
\text { techniques and processes created the } \\
\text { need to replace the existing systems of } \\
\text { decision support }\end{array}$ & 42 & 1 & 5 & 2.47 & 1.19 \\
\hline $\begin{array}{l}\text { The existing systems of decision } \\
\text { support have not been reliable }\end{array}$ & 42 & 2 & 5 & 4.09 & 1.01 \\
\hline $\begin{array}{l}\text { The existing systems of decision } \\
\text { support have not provided reliable, } \\
\text { useful and relevant information to the } \\
\text { process of decision-making }\end{array}$ & 42 & 2 & 5 & 4.24 & 0.93 \\
\hline
\end{tabular}

As can be seen from these results, the need for more accurate, reliable, relevant and timely information (mean=4.28) were the most important reason to implement DW. According to these figures, the existing systems of decision support have not provided reliable, useful and relevant information to the process of decision-making (mean=4.24) were the next second important reason to implement DW. Other important reasons include the existing systems of decision support have not been reliable (mean $=4.09$ ) and there is a dearth of reliable information for taking decisions (mean=4.07). From the data in the table, it is apparent that the highly competitive environment created the need to replace the existing systems of decision support and changes in manufacturing technology, techniques and processes created the need to replace the existing systems of decision support mean $=2.59$ and 2.47 respectively were the least important reasons to implement DW.

The researchers believe that some of the keys to measure success are satisfaction and approval. This is why it is essential that DW (if it is to be a success) must satisfy the needs (requirements) of its users. Similarly, the users need to be satisfied of the need for DW. To measure the success of implementing DW, the respondents, who their firms implemented DW (42 respondents), were solicited for their opinions regarding the derived satisfactions from implementing DW. A seven-point scale from 1 (strongly disagree) to 7 (strongly agree) was used to measure these responses. Table 2 shows that the great majority of respondents, since the least mean is 5.43, are very satisfied with the derived benefits of implementing DW. As can be seen from these results , most of the respondents believe that DW is useful in making better business decisions (mean=6.69). 
Table 2. The degree of satisfaction from implementing DW (Source: the figures are based on the responses to question 12 appendix A.

\begin{tabular}{|l|r|r|r|r|r|}
\hline $\begin{array}{l}\text { Satisfaction and approval of } \\
\text { implementing DW }\end{array}$ & NO. & Min. & Max. & Mean & SD \\
\hline $\begin{array}{l}\text { The information in your firm's DW is } \\
\text { sufficient for taking sound decisions }\end{array}$ & 42 & 4 & 7 & 6.14 & 0.89 \\
\hline $\begin{array}{l}\text { You are content with the benefits of } \\
\text { your firm's DW }\end{array}$ & 42 & 4 & 7 & 6.26 & 0.85 \\
\hline $\begin{array}{l}\text { The DW's information meets the } \\
\text { requirements of your task }\end{array}$ & 42 & 5 & 7 & 6.17 & 0.86 \\
\hline DW is a reliable source of information & 42 & 4 & 7 & 6.21 & 0.95 \\
\hline $\begin{array}{l}\text { DW's information is beneficial to } \\
\text { different areas of decisions }\end{array}$ & 42 & 4 & 7 & 6.19 & 0.83 \\
\hline $\begin{array}{l}\text { DW's information is used in different } \\
\text { areas of decisions }\end{array}$ & 42 & 5 & 7 & 6.14 & 0.81 \\
\hline $\begin{array}{l}\text { The DW offers user-friendly query } \\
\text { capability to decision-makers }\end{array}$ & 42 & 3 & 7 & 5.83 & 1.10 \\
\hline DW is a reliable information system & 42 & 4 & 7 & 6.02 & 1.04 \\
\hline $\begin{array}{l}\text { DW is a user-friendly information } \\
\text { system }\end{array}$ & 42 & 3 & 7 & 5.43 & 1.32 \\
\hline $\begin{array}{l}\text { DW is useful in making better business } \\
\text { decisions }\end{array}$ & 42 & 5 & 7 & 6.69 & 0.66 \\
\hline DW is useful for decision maker's task & 42 & 5 & 7 & 6.62 & 0.62 \\
\hline $\begin{array}{l}\text { DW can output information much more } \\
\text { quickly }\end{array}$ & 42 & 5 & 7 & 6.33 & 0.72 \\
\hline $\begin{array}{l}\text { The benefits of implementing DW } \\
\text { exceed its cost }\end{array}$ & 42 & 4 & 7 & 6.14 & 0.89 \\
\hline
\end{tabular}

As can be seen from these results, the need for more accurate, reliable, relevant and Moreover, the figures show clearly that the involved respondents were very satisfied on the grounds that DW is useful for decision maker's task (mean=6.62), DW can output information much more quickly (mean=6.33) and if the users content with the benefits of their firm's DW (mean=6.26). Other high responses include DW's information met the requirements of the respondents' task (mean=6.17), DW's information is beneficial to different areas of decisions(mean=6.19), DW is a reliable source of information (mean=6.21), the benefits of implementing DW exceed its cost (mean=6.14) and the DW's information is sufficient for taking sound decisions (mean=6.14). According to these figures, DW is a user-friendly information system (mean=5.43) and The DW offers user-friendly query capability to decision-makers (mean $=5.83$ ) were the least responses.

Based on these figures, it can be concluded that the implementation of DW (in Jordanian firms) is very useful and have a great positive effect on the process of decision-making. These results are similar to some previous studies' results on DW, for example, [13] and [11]. 


\section{Conclusion}

The evidences, which are obtained by analyzing the data from the questionnaires, reveal exceptionally remarkable facts, first of all and to some extent, the percentage of implementing DW is high $(35 \%)$ by comparison with other countries. one consequence of implementing DW was the great role of DW's information in enhancing and facilitating the process of decision-making. The results showed that the Jordanian firms benefited greatly from implementing DW. The results also revealed that the DW is a fruitful source of information. Moreover, the implementation of DW proved to be a success through helping decision-makers in taking fact-based decisions. Furthermore, the DW was lauded by the users for the successful use of its information as a basis for decision-making.

This study has humbly contributed to the field of scientific research in general and the field of decision support systems (DSS) in particular in many ways, first of all, the studies on the implementation of DW were nearly all in developed countries. This study was applied in Jordan, which is one of the developing countries in the Middle East. Therefore, the results of this study made a humble contribution to the existing knowledge in the field of implementing DW worldwide in general and in Jordan in particular. Second, there is a need for evidences that the DW improves the quality and accessibility to information. Therefore, this study practically investigated whether or not the implementation of DW improves the quality and accessibility to information and facilitates the decision-makers' tasks. Lastly, based on extensive literature review, the researchers have identified that firms are often unsuccessful due to a lack of appropriate information. For this reason, this study is one of the few empirical studies which have attempted to examine the effect of DW on decision effectiveness. In addition, previous research has not empirically tested its effectiveness in DSS contexts in Jordanian firms "to the researchers' knowledge".

Despite the usefulness and positive contributions of the study's results, these results should be treated and interpreted with caution. In fact, the study's sample included only the Jordanian firms which are listed on ASE. As a consequence, this might severely restrict the generalization of the results. It is believed that the results of this study might have been dissimilar, if all Jordanian firms have been surveyed. Therefore, prospective researchers are recommended to broaden the scope of their investigation to include all Jordanian firms.

\section{References}

1. Hayen, R. L. Rutashobya, C. D., Vetter, D. E.: An investigation of the factors affecting data warehousing success, Issues in Information Systems, Vol. 8, No. 2 (2007) 547-53.

2. Ang, J., Teo, T.S.H.: Management issues in data warehousing: insights from the Housing and Development Board, Decision Support Systems, 29 ( 2000) 11-20.

3. Shin, B.: An exploratory investigation of system success factors in data warehousing, Journal of the Association for Information Systems, Vol. 4 (2003) 141-170.

4. Park, Y.-T.: An empirical investigation of the effects of data warehousing on decision performance, Information \& Management, 43 ( 2006) 51-61. 
5. Mukherjee, D., D’Souza, D.: Think phased implementation for successful data warehousing, information systems management, Spring (2003) 82-90.

6. Eckerson, W.: Evolution of Data Warehousing: The Trend toward Analytical Applications, Journal of Data Warehousing, Vol. 25, No. 1 (2003) 1-8.

7. Briggs, D.: A Critical Review of Literature on Data Warehouse Systems Success/Failure, Journal f Data Warehousing, Vol. 49, No. 3 (2002) 1 - 20.

8. Shankaranarayanan, G., Cai, Y.: Supporting data quality management in decision-making, Decision Support Systems 42 (2006) 302-317.

9. Rudra, A., Yeo, E.: Issues in User Perceptions of Data Quality and Satisfaction in Using a Data Warehouse - An Australian Experience, Proceedings of the 33rd Hawaii International Conference on System Sciences, IEEE (2000) 1-7.

10. Hegazy, F., Ghorab, K..: The impact of system support on adoption \& diffusion of data warehousing success, 2003, http://www.hicbusiness.org/biz2003proceedings, accessed $31 / 08 / 2011$.

11. Aljanabi, A., Alhamami, A., Alhadidi, B.: Query Dispatching Tool Supporting Fast Access to Data Warehouse, The International Arab Journal of Information Technology, Vol. 10, No. 3, May (2013) 269-275.

12. Wixom, B. H., Watson, H. J.: An empirical investigation of the factors affecting data warehousing success, MIS Quarterly, Vol. 25, No. 1 (2001) 17-41.

13. Gimzauskiene, E., Valanciene, L.: Efficiency of Performance Measurement System: The Perspective of Decision Making, economics and management, 15 (2010) 917-923.

14. Mansouri, S., Gallear, A. D., Askariazad, M. H.: Decision support for build-to-order supply chain management through multiobjective optimization, International Journal of Production Economics, 135 (2012) 24-36.

15. McKenna, J. P.: Moving Toward Real-Time Data Warehousing, business intelligence Journal, Vol. 16, No. 3 (2011) 14-19.

16. Au, N., Ngai, E. W. T., Cheng T. C. E.: Extending the Understanding of End User Information Systems Satisfaction Formation: An Equitable Needs Fulfillment Model Approach, MIS Quarterly, Vol. 32, Issue 1 (2008) 43-66.

17. Rasmussen, N., Goldy, P. S., Solli P. O.: Financial Business Intelligence Trends, Technology, Software Selection, and Implementation, John Wiley and Sons, Inc., New York, (2002).

18. Watson, H. J., Haley, B. J.: Data warehousing: A framework and survey of current practices, Journal of Data Warehousing, Vol. 2, No. 1 (1997) 10-17.

19. Gatziu, S., Vavouras, A.: Data Warehousing: Concepts and Mechanisms, Informatik, Informatique 1 (1999).

20. Doherty, N. F., Doig, G.: The role of enhanced information accessibility in realizing the benefits from data warehousing investments, Journal of Organizational Transformation and Social Change, Vol. 8, No 2 (2011) 163-182.

21. Ballard, C., Herreman, D., Schau, D., Bell, R., Kim, E., Valencic, A.: Data Modeling Techniques for Data Warehousing, International Business Machines Corporation(IBM Corp), 1st edition (1998).

22. Watson, H,. Fuller J. C., Ariyachandra, T.: Data warehouse governance: best practices at blue cross and blue shield of North Carolina, Decision Support Systems archive, Vol. 38, Issue 3, December (2004) $435-450$.

23. Ahmad, I., Azhar, S.: Data Warehousing in Construction: From Conception to Application, Proceedings of the First International Conference on Construction in the Twenty First Century, Miami, Florida, USA, April (2002).

24. List, B., Bruckner, Machaczek, R. K., Schiefer, J.: A Comparison of Data Warehouse Development Methodologies - Case Study of the Process Warehouse, DEXA, Munich (2002). 
25. Nemati, H. R., Steiger, D. M., Iyer, L. S., Herschel, R. T.: Knowledge warehouse: an architectural integration of knowledge management, decision support, artificial intelligence and data warehousing, Decision Support Systems, Vol. 33, Issue 2, June (2002) 143-161.

26. Mannino, M. V., Hong, S. N., Choi, I. J.: Efficiency evaluation of data warehouse operations, Decision Support Systems, Vol. 44, No. 4 (2008) 883-898.

27. Bȩbel, B., Eder, J. Koncilia, C., Morzy, T., Wrembel, R.: Creation and management of versions in multiversion data warehouse, Proceedings of the 2004 ACM symposium on Applied computing, SAC 2004, March 14-17, Nicosia, Cyprus, (2004) 717-723.

28. Brown, T.: Data Warehouse Implementation with the SAS System, SAS Institute Inc., Dallas, TX, 1996, http://www2.sas.com/proceedings/sugi22/dataware/paper132.pdf.

29. Ramamurthy, K. R, Sen, A., Sinha, A. P.: An empirical investigation of the key determinants of data warehouse adoption, Decision Support Systems, 44 (2008) 817-841.

30. Nilakanta, S., Scheibe, K., Rai, A.: Dimensional issues in agricultural data warehouse designs, computers and electronics in agriculture, 60 (2008) 263-278.

31. Chmiel J., Morzy, T,. Wrembel, R:. Multiversion join index for multiversion data warehouse, Information and Software Technology archive, Vol. 51, Issue 1, January (2009) 98-108.

32. Hackathorn, R.: Current Practices in Active Data Warehousing, Bolder Technology, Inc., (2002).

33. Watson, H., Haley, B.: Managerial Considerations, In Communications of the ACM, Vol. 41, No. 9, September (1998) 32-37.

34. Watson, H. J., Goodhue, D., Wixom, B.H.: The benefits of data warehousing: why some organizations realize exceptional payoffs, Information \& Management, (2001a) 1-12.

35. Watson, H., Ariyachandra, T., Matyska, Jr, R. J.: Data Warehousing Stages of Growth, Information Systems Management, Vol. 18, Issue 3, June (2001b) 42-50.

36. Wells, J. D., Hess, T. J.: Understanding decision-making in data warehousing and related decision support systems: An Explanatory Study of Customer Relationship Management Application, Information Resources Management Journal, Vol. 15, No. 4, OctoberDecember (2002) 16-32.

37. Abdel Hafez, H. A., Kamel, S.: Web Based Data Warehouse in the Egyptian Cabinet Information and Decision Support Center, Decision Support in an Uncertain and Complex World: The IFIP T C8/WG8.3 International Conference (2004) 402-409.

38. Rubin, D. L., Desser, T . S.: A Data Warehouse for Integrating Radiologic and Pathologic Data, Journal of the American College of Radiology, Vol. 5, No. 3, March (2008) 210-217.

39. Mawilmada, P. K.: Impact of a data warehouse model for improved decision-making process in healthcare. Masters by Research thesis, Queensland University of Technology, October (2011).

40. Ojeda-Castro, Á, Ramaswamy, M., Rivera-Collazo, Á., Jumah, A.: Critical Factors For Successful Implementation Of Data Warehouses, Issues in Information Systems, Vol. 12, No. 1 ( 2011) 88-96.

41 Alshboul, R:. Data Warehouse Explorative Study, Applied Mathematical Sciences, Vol. 6, No. 61 (2012) 3015- 3024.

42. Shen, L., Liu, S., Chen, S., Wang, X.: The Application Research of OLAP in Police Intelligence Decision System, Procedia Engineering 29 (2012) 397 - 402.

43. Shams, K., Farishta, M. Data warehousing: toward knowledge management, Topics in Health Information Management, Vol. 21, No. 3, February (2001) 24-32.

44. Chenoweth, T., Corral, K., Demirkan, H.: Seven Key Interventions for data warehouse success, Communications of the ACM, Vol. 49, No. 1, January (2006) 115-119.

45. DeLone, W.H., McLean, E.R.: Information systems success: the quest for the dependent variable, Information Systems Research, Vol. 3, No. 1 (1992) 60-95.

46. Kumar, R. L.: Justifying Data Warehousing Investments, in Data Warehousing and Web Engineering, Shirley Becke (ed), (2002) 100-102. 
47. Watson, H. J., Gerard, J.G., Gonzalez, L.E., Haywood, M.E., Fenton, D.: Data warehousing failures: case studies and findings, Journal of Data Warehousing, Vol. 4, No. 1, Spring (1999) 44-55.

48. Sammon, D., Adam, F., Carton, F.: Benefit Realisation through ERP: The Re-Emergence of Data Warehousing, Electronic Journal of Information Systems Evaluation, Vol. 6, Issue 2 (2003) 155-16.

49. Aguila, M. D., Felber, E.: Data Warehouses and Evidence-Based Dental Insurance Benefits, Journal of Evidence Based Dental Practice, Vol. 4, Issue 1 (2004) 113-119.

50. Devlin, B.: Data Warehouse from Architecture to Implementation, Addison Wesley Longman, Inc., (1997).

51. Griffin, R. K.: Data warehousing, Cornell Hotel and Restaurant Administration Quarterly, Vol. 39, No. 4 (1998) 28-40.

52. Wilkoff, N., Pohlmann, T ., Hudson, R., Lambert, N.: The State Of Technology Adoption, Business Technographics North America, May 5 (2004) Forrester Research, Inc.

53. Agosta, L.: Hub-and- Spoke Architecture Favored, DM Review, Vol. 15, Issue 3, March (2005) 14-63.

54. Hwang, H.-G., Ku, C.-Y., Yen, D. C., Cheng, C.-C.: Critical factors influencing the adoption of data warehouse technology: a study of the banking industry in Taiwan, Decision Support Systems, 37 (2004) 1-21.

55. Hong, S., Katerattanakul, P., Hong, S.-K., Cao, Q.: Usage and perceived impact of data warehouses: a study in Korean financial companies, International Journal of Information Technology \& Decision Making, Vol. 5, No. 2 (2006) 297-315.

56. Agosta, L,. Andrews, M., Ritzmann, M.: The Data Warehouse Satisfaction Survey, Part 1: The Number One Complaint About Data Warehousing, Information Management Special Reports, October 2 (2007).

57. Merritt, K. L.: User Satisfaction In Data warehousing: An Empirical Investigation Of Salient Variables, Issues in Information Systems, Vol. 9, No. 2 (2008) 500-508.

58. Wixom, B. H., Watson, H. J., Reynolds, A. M., Hoffer, J. A.: Continental Airlines Continues to Soar with Business Intelligence, Information Systems Management, 25 (2008) $102-112$.

59. Almabhouh, A., Saleh, A. R., Azizah, A.: Examining the Influence of Relationship Quality on Data Warehouse Success, International Journal of Modeling and Optimization, Vol. 1, No. 5, December (2011) 402-409.

60. Lodico, M. G., Spaulding, D. T., Voegtle, K. H.: Methods In Educational Research From Theory to Practice, John Wiley \& Sons, Inc., San Francisco, CA, (2006).

61. AL-allak, B.: Evaluating the Adoption and Use of Internet-based Marketing Information Systems to Improve Marketing Intelligence (The Case of Tourism SMEs in Jordan), International Journal of Marketing Studies, Vol. 2, No. 2, November (2010) 87- 101.

62. Khattab, A.: Al The Role of Corporate Risk Managers in Country Risk Management: A Survey of Jordanian Multinational Enterprises, International Journal of Business and Management, Vol. 6, No. 1, January (2011) 274-282.

63. Chongruksut, W.: the adoption of activity-based costing in Thailand, doctoral thesis, Faculty of Business and Law, Victoria University (2002).

64. Lee, Y. W., Strong, D. M., Kahn, B. K., Wang, R. Y.: AIMQ: a methodology for information quality assessment, Information \& Management 40 (2002) 133-146.

65. AbuShanab, E., Pearson, J. M., Setterstrom, A. J.: Internet Banking and Customers' Acceptance in Jordan: The Unified Model's Perspective, Communications of the Association for Information Systems, Vol. 26, Article 23, April (2010) 493-524.

66. Alhawary, F. A., Abommman, A. H:. Measuring the Effect of Academic Satisfaction on Multi-Dimensional Commitment: A Case Study of Applied Science Private University in Jordan, International Business Research, Vol. 4, No. 2, April (2011) 153-160. 
67. Maqbool-ur-Rehman, S.: Which Management Accounting Techniques Influence Profitability in the Manufacturing Sector of Pakistan?, Pakistan Business Review April (2011) 53- 105.

68. Ramakrishnan, T., Jones, M. C., Sidorova, A.: Factors influencing business intelligence (BI) data collection strategies: An empirical investigation, Decision Support Systems, 52 (2012) 486-496.

69. Saban, M., Efeoğlu, Z.: An Examination of the Effects of Information Technology on Managerial Accounting in the Turkish Iron and Steel Industry, International Journal of Business and Social Science, Vol. 3, No. 12, Special Issue - June (2012) 105-117.

70. Ebimobowei, A., Binaebi, B.: Analysis of Factors Influencing Activity-Based Costing Applications in the Hospitality Industry in Yenagoa, Nigeria, Asian Journal of Business Management, Vol. 5, No. 3 (2013) 284-290.

71. Hardan, A. S., Shatnawi, T. M.: Impact of Applying the ABC on Improving the Financial Performance in Telecom Companies, International Journal of Business and Management, Vol. 8, No. 12 (2013) 48-61.

72. Gerber, S. B., Finn, K. V.: Using SPSS For Windows Data Analysis and Graphics, 2nd Edition, Springer Science Business Media, Inc., (2005).

73. Pallant, J. F.: SPSS survival manual: a step by step guide to data analysis using SPSS for Windows (Version 12), 2nd edition 2005, Allen \& Unwin, Australia.

74. George, D., Mallery, P.: SPSS for Windows Step-by-Step: A Simple Guide and Reference, 14.0 update, 7th Edition 2006, Allyn \& Bacon.

\section{Appendix A}

Part 1: The personal details and demographics of respondents

1. Please give your name, title and Email:

Note: This question is optional

2. Please indicate which sex you are.

A. Male

B. Female

3. Which age bracket are you?

A. Less than 40

B. 40 to 45

C. 46 to 50

D. 51 to 55

E. 56 to 60

F. More than 60

4. Please indicate what level of education you achieved.

A. General certificate of secondary education

B. A graduate degree (bachelor's)

C. A postgraduate degree (master's)

D. A PhD degree (doctorate)

5. Please indicate your years of experience at the senior management level.

A. Less than 3 years

B. 3-6 years

C. 7-10 years

D. 11-14 years

E. More than 14 years

Part 2: The company's details 
6. Your company belongs to which of the following 22 industrial groups. Please tick the appropriate group.

1. Banks

2. Chemical industries

3. Commercial services

4. Educational services

5. Electric industries

6 . Engineering and construction

7. Financial services

8. Food and beverages

9. Glass and ceramic industries

10. Health care services

11. Hotels and Truism

12. Insurance

13. Mining and extraction industries

14. Paper and cardboard industries

15. Pharmaceutical and medical industries

16. Printing and packaging

17. Real estate

18. Technology, communications and media

19. Textiles, leather and clothing

20. Tobacco and cigarette

21. Transportation

22. Utilities and energy

7. Please indicate the number of employees in your entire firm, including all of its branches, divisions and subsidiaries.

A. Less than 100

B. $100-500$

C. $501-900$

D. $901-1300$

E. $1301-1700$

F. $1701-2100$

G. 2101-2500

H. More than 2500

8. The paid-up capital of your firm is:

A. Less than $\$ 1$ million

B. $\$ 1 \mathrm{~m}$ to less than $\$ 10$ million

C. $\$ 10 \mathrm{~m}$ to less than 20 million

D. $\$ 20 \mathrm{~m}$ to less than $\$ 100$ million

E. $\$ 100 \mathrm{~m}$ to less than $\$ 500$ million

F. $\$ 500 \mathrm{~m}$ to less than $\$ 1$ billion

G. 1 bn to less than $\$ 10$ billion

H. 10 billion or more

9. Please indicate the annual revenue of your firm in the US dollars?

A. Less than $\$ 500,000$

B. $\$ 500,000$ to less than $\$ 1$ million

C. $\$ 1 \mathrm{~m}$ to less than $\$ 20$ million

D. $\$ 20 \mathrm{~m}$ to less than $\$ 100$ million

E. $\$ 100 \mathrm{~m}$ to less than $\$ 500$ million

F. $\$ 500 \mathrm{~m}$ to less than $\$ 1$ billion

G. $\$ 1$ billion or more

Part 3: Questions regarding the implementation of data warehouse (DW) 
10. Has your firm fully implemented DW and using it as a part of daily practices?

A. Yes

B. No (please go to question11)

11. How important these reasons in the decision to implement DW? Please check the appropriate box or boxes.

\begin{tabular}{|l|l|l|l|l|l|}
\hline & & & & & \\
\hline A. & $\begin{array}{l}\text { There is a dearth of reliable information for taking } \\
\text { decisions. }\end{array}$ & $\begin{array}{l}\text { The highly competitive environment created the need to } \\
\text { replace the existing systems of decision support. }\end{array}$ & & & \\
\hline C. & $\begin{array}{l}\text { The need for more accurate, reliable, relevant and timely } \\
\text { information. }\end{array}$ & & & & \\
\hline D. & $\begin{array}{l}\text { Changes in manufacturing technology, techniques and } \\
\text { processes created the need to replace the existing systems } \\
\text { of decision support. }\end{array}$ & & & & \\
\hline E. & $\begin{array}{l}\text { The existing systems of decision support have not been } \\
\text { reliable. }\end{array}$ & & & & \\
\hline F. & $\begin{array}{l}\text { The existing systems of decision support have not provided } \\
\text { reliable, useful and relevant information to the process of } \\
\text { decision-making. }\end{array}$ & & & & \\
\hline
\end{tabular}

12. To what extent do you agree or disagree with these issues? Please tick the appropriate box or boxes.

\begin{tabular}{|l|l|l|l|l|l|l|l|}
\hline & & (n) & & & & \\
\hline A. & $\begin{array}{l}\text { The information in your firm's DW is sufficient for } \\
\text { taking sound decisions }\end{array}$ & & & & & \\
\hline B. & $\begin{array}{l}\text { You are content with the benefits of your firm's } \\
\text { DW }\end{array}$ & & & & & \\
\hline C. & $\begin{array}{l}\text { The DW's information meets the requirements of } \\
\text { your task }\end{array}$ & & & & & \\
\hline D. & DW is a reliable source of information & & & & & & \\
\hline E. & $\begin{array}{l}\text { DW's information is beneficial to different areas of } \\
\text { decisions }\end{array}$ & & & & & & \\
\hline F. & $\begin{array}{l}\text { DW's information is used in different areas of } \\
\text { decisions }\end{array}$ & & & & & & \\
\hline G. & $\begin{array}{l}\text { The DW offers user-friendly query capability to } \\
\text { decision-makers }\end{array}$ & & & & & \\
\hline H. & DW is a reliable information system & & & & \\
\hline I. & DW is a user-friendly information system & & & & & & \\
\hline J. & DW is useful in making better business decisions & & & & & & \\
\hline K. & DW is useful for decision maker's task & & & & & & \\
\hline L. & DW can output information much more quickly & & & & & & \\
\hline M. & The benefits of implementing DW exceed its cost & & & & & & \\
\hline
\end{tabular}

